\title{
ZnO CO-DOPED WITH Ni AND Mg: PREPARATON BY CO- PRECIPITATION, CHARACTERISATION AND EFFECT OF AMOUNT OF THE CO-DOPANTS ON THE BANDWIDTH OF ZnO
}

\author{
K. M. Sreedhar ${ }^{1}$, Sangeeth Sivan ${ }^{1}$, Karthik Raja ${ }^{1}$, Kirti Suresh ${ }^{1}$, \\ R. Sreelekshmi ${ }^{1}$, Appu Palat ${ }^{1}$ and K. M. Sreekanth ${ }^{2, 凶}$ \\ ${ }^{1}$ Department of Chemistry, Amrita School of Arts and Sciences, Amrita Vishwa Vidyapeetham, \\ Amritapuri Campus, Vallikkavu, Clappana P. O., Kollam, Kerala - 690525, India \\ ${ }^{2}$ Department of Sciences, Amrita School of Engineering, Amrita Vishwa Vidyapeetham, \\ Ettimadai Campus, Coimbatore, Tamil Nadu - 641112, India \\ ${ }^{\circledR}$ Corresponding Author: km_sreekanth@cb.amrita.edu
}

\begin{abstract}
Owing to the significance of semiconducting transition metal oxides, doped with transition metals, in the area of spintronics, we prepared zinc oxide co-doped with nickel and magnesium, following chemical co-precipitation strategy. Since our focus was also to look at the effect of the amount of the co-dopants on the bandwidth of zinc oxide, we prepared six different samples of zinc oxide co-doped with nickel and magnesium, varying the amount of the co-dopants. The prepared samples were characterized following Energy Dispersive X-ray Analysis, powder Xray Diffraction Analysis and solid-state UV-visible spectral analysis. The Tau plots were utilized for the determination of the band width of all the prepared samples. The bandwidth of all the prepared samples thus obtained was compared with the bandwidth of pure undoped zinc oxide. For this, we also prepared pure undoped zinc oxide following a chemical precipitation strategy. It was observed that the bandwidth of all the prepared samples, zinc oxide co-doped with nickel and magnesium, is greater than that of the pure undoped zinc oxide that we prepared. Again, we observed that the bandwidth of pure zinc oxide increases as the amount of nickel and magnesium in the crystal lattice of zinc oxide increases.
\end{abstract}

Keywords: Zinc Oxide ,Co-doped Metal Oxides, Bandwidth, Tau Plot, Energy Dispersive X-ray Analysis

RASĀYAN J. Chem., Vol. 14, No.2, 2021

\section{INTRODUCTION}

The area, electronics is exclusively based on the manipulation of the negative charge of the electron, and here the spin of the electron is not taken into account. However, in spintronics, the spin or the spin and the charge together are considered, and the spin of the electron is manipulated for carrying the information. To find application in the field of spintronics, a material is supposed to exhibit ferromagnetism at room temperature. In this scenario, the so-called half-metallic oxides are of greater significance. ${ }^{1,2}$ Again, the so-called dilute magnetic semiconductors are also suitable for spintronics. These are generated by doping the semiconductors with magnetic impurities. ${ }^{3,4}$ By doping with magnetic impurities, it is possible to alter the bandwidth and ferromagnetic properties of these semiconductors. The bandwidth engineering and tuning of ferromagnetic properties in the oxides of transition metals are possible without doping with magnetic impurities. It is achieved by doping these oxides with various transition metals. A large number of reports are available on the bandwidth engineering and tuning of room temperature ferromagnetic properties of the transition metal oxide, $\mathrm{ZnO}$, where the bandwidth and ferromagnetic properties of this oxide are altered doping with other d-block metals or f-block metals. ${ }^{5-16}$ There are reports from our group on the bandwidth engineering of $\mathrm{ZnO}$ and studies on the photocatalytic properties of the doped $\mathrm{ZnO} \cdot{ }^{17-19}$ A large volume of work in this area is carried out with $\mathrm{ZnO}$ because of its very interesting properties and easy tunability of band width. ${ }^{20-24}$ 
RASĀYAN J. Chem.

Vol. 14 | No. 2 |1289-1296| April - June | 2021

\section{Chemicals and Reagents Used}

\section{EXPERIMENTAL}

All the chemicals and reagents used are of either Laboratory Reagent (LR) grade or Analytical Reagent (AR) grade. They were used as such without further purification. The various reagents used in the present work include $\mathrm{ZnSO}_{4} .7 \mathrm{H}_{2} \mathrm{O}$ (NICE, LR grade), $\mathrm{CaSO}_{4} .2 \mathrm{H}_{2} \mathrm{O}$ (NICE, LR grade), $\mathrm{MgSO}_{4} .7 \mathrm{H}_{2} \mathrm{O}$ (NICE, AR grade), $\mathrm{NiSO}_{4} \cdot 6 \mathrm{H}_{2} \mathrm{O}$ (NICE, LR grade) and $\mathrm{NaOH}$ (MERK). For the preparation of various solutions and the washing of the final products, demineralized water was used.

\section{Preparation of Pure ZnO}

To a solution of $11.506 \mathrm{~g}$ of $\mathrm{ZnSO}_{4} .7 \mathrm{H}_{2} \mathrm{O}$ in $100 \mathrm{ml}$ demineralized water, kept at constant stirring over a magnetic stirrer at room temperature, a solution of $3.296 \mathrm{~g}$ of NaOH in $50 \mathrm{ml}$ demineralized water was added slowly in a thin stream. It was kept for 15 minutes in the stirring condition. The precipitated $\mathrm{Zn}(\mathrm{OH})_{2}$ was filtered through a sintered glass crucible, G4. The precipitate was washed with demineralized water till the washings were free from $\mathrm{Zn}^{+2}$ ions, $\mathrm{SO}_{4}{ }^{-2}$ ions and unreacted $\mathrm{NaOH}$. The presence of $\mathrm{NaOH}$ in the washings was checked with a solution of phenolphthalein (no pink or pale pink color). A solution of $\mathrm{BaCl}_{2}$ was used to confirm that the washings are free from $\mathrm{SO}_{4}{ }^{-2}$ ions (no white precipitate of $\mathrm{BaSO}_{4}$ or milky appearance). When the washings, after acidification with dilute $\mathrm{H}_{2} \mathrm{SO}_{4}$, were treated with a drop of cobalt nitrate solution and ammonium mercuric thiocyanate reagent, no paleblue precipitate or color was developed indicating the absence of $\mathrm{Zn}^{+2}$ ions in the washings. The precipitate was finally washed with acetone and dried in an air oven at $50{ }^{\circ} \mathrm{C}$. Thermal decomposition of $\mathrm{Zn}(\mathrm{OH})_{2}$ at $100{ }^{\circ} \mathrm{C}-250{ }^{\circ} \mathrm{C}$ yields $\mathrm{ZnO}$. In this work, the dried precipitate of $\mathrm{Zn}(\mathrm{OH})_{2}$ was taken in a silica crucible and was heated in a muffle furnace to $150{ }^{\circ} \mathrm{C}$ from room temperature and kept at $150{ }^{\circ} \mathrm{C}$ for 2 hours. After 2 hours, the furnace was switched off and allowed to cool along with the sample to room temperature. The $\mathrm{ZnO}$ thus obtained was powdered and used for further study.

\section{Preparation of $\mathrm{ZnO}$ Co-doped with $\mathrm{Ni}$ and $\mathrm{Mg}$}

To a solution of $2.875 \mathrm{~g}$ of $\mathrm{ZnSO}_{4} .7 \mathrm{H}_{2} \mathrm{O}, 0.2628 \mathrm{~g}$ of $\mathrm{NiSO}_{4} .6 \mathrm{H}_{2} \mathrm{O}$ and $0.7394 \mathrm{~g}$ of $\mathrm{MgSO}_{4} .7 \mathrm{H}_{2} \mathrm{O}$ in 100 $\mathrm{ml}$ demineralized water, kept at constant stirring over a magnetic stirrer at room temperature, a solution of $0.8 \mathrm{~g}$ of $\mathrm{NaOH}$ in $50 \mathrm{ml}$ demineralized water was added slowly in a thin stream. It was kept at the constant stirring condition for 15 minutes. The precipitated $\mathrm{Zn}(\mathrm{OH})_{2}$ co-doped with $\mathrm{Ni}(\mathrm{OH})_{2}$ and $\mathrm{Mg}(\mathrm{OH})_{2}$ was filtered through a sintered glass crucible, G4. The precipitate was washed with demineralized water till the washings were free from $\mathrm{Zn}^{+2}$ ions, $\mathrm{SO}_{4}{ }^{-2}$ ions, $\mathrm{Ni}^{+2}$ ions, $\mathrm{Mg}^{+2}$ ions and unreacted $\mathrm{NaOH}$. The washings were checked for the presence or absence of the species $\mathrm{Zn}^{+2}$ ions, $\mathrm{SO}_{4}{ }^{-2}$ ions and unreacted $\mathrm{NaOH}$ as explained under preparation of pure $\mathrm{ZnO}$. When the washings were treated with a few drops of dimethyl glyoxime reagent, after adding a few drops of $\mathrm{NH}_{4} \mathrm{Cl}$ and $\mathrm{NH}_{4} \mathrm{OH}$ solutions, no rose-red precipitate or color was developed indicating the absence of nickel ions. The washings were heated with a few drops of $\mathrm{NH}_{4} \mathrm{Cl}$ solution and ammoniacal oxime reagent when no pale-yellow precipitate or color was formed indicating the absence of magnesium ions in the washings. The precipitate was finally washed with acetone and dried in an air oven at $50{ }^{\circ} \mathrm{C}$. Thermal decomposition of $\mathrm{Zn}(\mathrm{OH})_{2}$ at $100{ }^{\circ} \mathrm{C}-250{ }^{\circ} \mathrm{C}$ yields $\mathrm{ZnO}, \mathrm{Ni}(\mathrm{OH})_{2}$ at $230{ }^{\circ} \mathrm{C}-360{ }^{\circ} \mathrm{C}$ yields $\mathrm{NiO}$ and $\mathrm{Mg}(\mathrm{OH})_{2}$ at $360{ }^{\circ} \mathrm{C}$ gives $\mathrm{MgO}$. In this work, the dried precipitate of $\mathrm{Zn}(\mathrm{OH})_{2}$ co-doped with $\mathrm{Ni}(\mathrm{OH})_{2}$ and $\mathrm{Mg}(\mathrm{OH})_{2}$ was taken in a silica crucible and was heated in a muffle furnace to $450{ }^{\circ} \mathrm{C}$ from room temperature and kept at $450{ }^{\circ} \mathrm{C}$ for 6 hours. After 6 hours, the furnace was switched off and allowed to cool along with the sample to room temperature. Keeping the amount of $\mathrm{ZnSO}_{4} .7 \mathrm{H}_{2} \mathrm{O}$ at $2.875 \mathrm{~g}$ and that of $\mathrm{NiSO}_{4} \cdot 6 \mathrm{H}_{2} \mathrm{O}$ at $0.2628 \mathrm{~g}$ in the feed, three more samples of $\mathrm{ZnO}$ co-doped with $\mathrm{Ni}$ and $\mathrm{Mg}$ were prepared, following the same procedure, taking $0.4929 \mathrm{~g}, 0.2464 \mathrm{~g}$ and $0.9859 \mathrm{~g}$ of $\mathrm{MgSO}_{4} .7 \mathrm{H}_{2} \mathrm{O}$, separately. Here the amount of $\mathrm{MgSO}_{4} .7 \mathrm{H}_{2} \mathrm{O}$ in the feed was varied. Similarly, keeping the amount of $\mathrm{ZnSO}_{4} .7 \mathrm{H}_{2} \mathrm{O}$ at $2.875 \mathrm{~g}$ and that of $\mathrm{MgSO}_{4} .7 \mathrm{H}_{2} \mathrm{O}$ at $0.2464 \mathrm{~g}$ in the feed, two more samples of $\mathrm{ZnO}$ co-doped with $\mathrm{Ni}$ and $\mathrm{Mg}$ were prepared to take $0.7885 \mathrm{~g}$ and $0.5257 \mathrm{~g}$ of $\mathrm{NiSO}_{4} \cdot 6 \mathrm{H}_{2} \mathrm{O}$, separately. Here the amount of $\mathrm{NiSO}_{4} \cdot 6 \mathrm{H}_{2} \mathrm{O}$ in the feed was varied. A total of six samples of $\mathrm{ZnO}$ co-doped with $\mathrm{Ni}$ and $\mathrm{Mg}$ (samples $\mathrm{A}, \mathrm{B}, \mathrm{C}, \mathrm{D}, \mathrm{E}$, and F) were prepared, as summarised in Table-1. All co-doped samples thus obtained were powdered and used for further study. 
RASĀYAN J. Chem.

Vol. 14 | No. 2 |1289-1296| April - June | 2021

Table-1: Amount of $\mathrm{ZnSO}_{4} .7 \mathrm{H}_{2} \mathrm{O}, \mathrm{NiSO}_{4} \cdot 6 \mathrm{H}_{2} \mathrm{O}$ and $\mathrm{MgSO}_{4} .7 \mathrm{H}_{2} \mathrm{O}$ in the Feed

\begin{tabular}{c|c|c|c}
\hline $\begin{array}{c}\text { Sample } \\
\text { Name }\end{array}$ & $\begin{array}{c}\text { Amount of } \mathrm{ZnSO}_{4} .7 \mathrm{H}_{2} \mathrm{O} \text { in } \\
\text { gram in the feed }\end{array}$ & $\begin{array}{c}\text { Amount of } \mathrm{NiSO}_{4} \cdot 6 \mathrm{H}_{2} \mathrm{O} \text { in } \\
\text { gram in the feed }\end{array}$ & $\begin{array}{c}\text { Amount of } \mathrm{MgSO}_{4} .7 \mathrm{H}_{2} \mathrm{O} \\
\text { in gram in the feed }\end{array}$ \\
\hline C & 2.875 & 0.2628 & 0.2464 \\
\hline B & 2.875 & 0.2628 & 0.4929 \\
\hline A & 2.875 & 0.2628 & 0.7394 \\
\hline F & 2.875 & 0.2628 & 0.9859 \\
\hline E & 2.875 & 0.5257 & 0.2464 \\
\hline D & 2.875 & 0.7885 & 0.2464 \\
\hline
\end{tabular}

\section{Characterization of the Samples}

\section{Energy Dispersive X-ray Analysis (EDAX)}

The elements present in the prepared samples were identified by Energy Dispersive X-ray Analysis, EDAX, using the instrument CARL ZEISS EVO 18 Secondary Electron Microscope with EDS. The elemental analysis was carried out with sample C.

\section{X-Ray Diffraction (XRD) Analysis}

For the characterization of the crystal structure of the pure undoped $\mathrm{ZnO}$ and co-doped $\mathrm{ZnO}$, powder $\mathrm{X}$ ray diffraction (powder XRD) analysis of the prepared samples was carried out on a BRUKER D8 Advance XRD instrument.

\section{UV-visible Spectral Analysis}

To determine the bandwidth of the prepared samples, the solid-state UV-visible spectral analysis of the samples was performed on a Shimadzu UV 2600 spectrophotometer.

\section{Elemental Analysis}

\section{RESULTS AND DISCUSSION}

The elemental analysis was carried out with sample $\mathrm{C}$. In sample $\mathrm{C}$, the expected elements include zinc $(\mathrm{Zn})$, nickel $(\mathrm{Ni})$, magnesium $(\mathrm{Mg})$ and oxygen $(\mathrm{O})$. The result of EDAX for sample $\mathrm{C}$ is presented in Fig.-1. The result confirms the presence of these elements in the prepared sample C. In addition to these expected elements, the sample also contains sulfur (S). The presence of $\mathrm{S}$ in the co-doped sample is confirmed by the peak between 2 and 3 on the abscissa in Fig.-1.

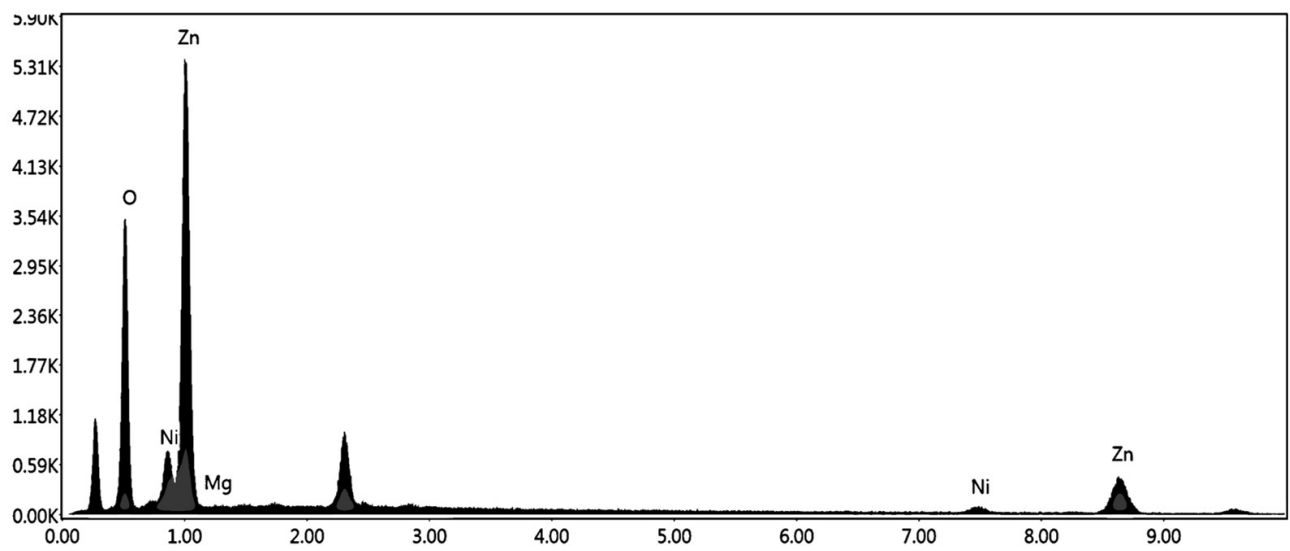

Fig.-1: EDAX of Sample C

\section{XRD Analysis}

The result of the slow scan powder XRD analysis of the prepared samples are presented in Fig.-3 and Fig.-4 along with the XRD analysis result of the pure undoped $\mathrm{ZnO}$, Fig.-2. The powder XRD patterns of the co-doped samples were recorded in the $2 \theta$ range of $10^{\circ}-80^{\circ}$. In all the $\mathrm{x}$-ray diffractograms, prominent XRD lines are observed at $2 \theta$ of $31.45,34.14,36.04,47.29,56.23,62.58,66.98,67.87$ and 
RASĀYAN J. Chem.

Vol. 14 | No. 2 |1289-1296| April - June | 2021

68.83. These lines could be indexed, respectively, as (100), (002), (101), (102), (110), (103), (200), (112) and (201). They correspond to the hexagonal wurtzite phase of ZnO [JCPDS 36-1451]. Therefore, undoped and co-doped samples possess hexagonal $\mathrm{ZnO}$ phase. ${ }^{25-27}$ Furthermore, the peaks below $30^{\circ}$ at the $2 \theta$ angle of 18.7, 20, 21.07, 22.38, 24, 25.06 etc. are perfectly in match with $\mathrm{Zn}_{3} \mathrm{O}\left(\mathrm{SO}_{4}\right)_{2}$ in the prepared co-doped samples (JCPDS card number 000321475). The presence of S in the co-doped sample is confirmed by the peak between 2 and 3 on the abscissa in the EDAX, Fig.-1.

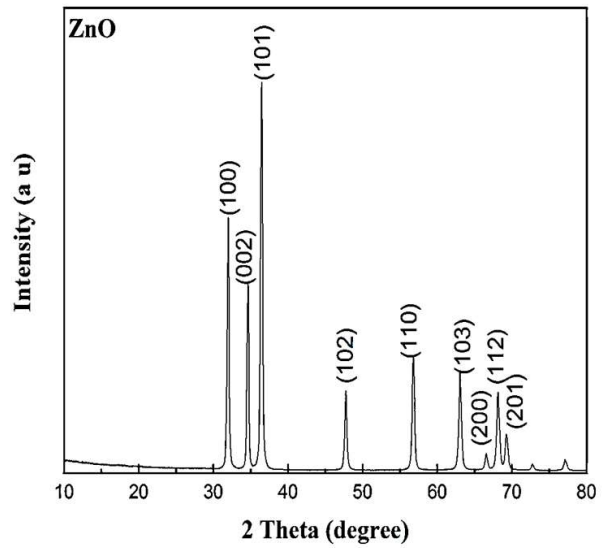

Fig.-2: XRD of Pure Undoped $\mathrm{ZnO}$

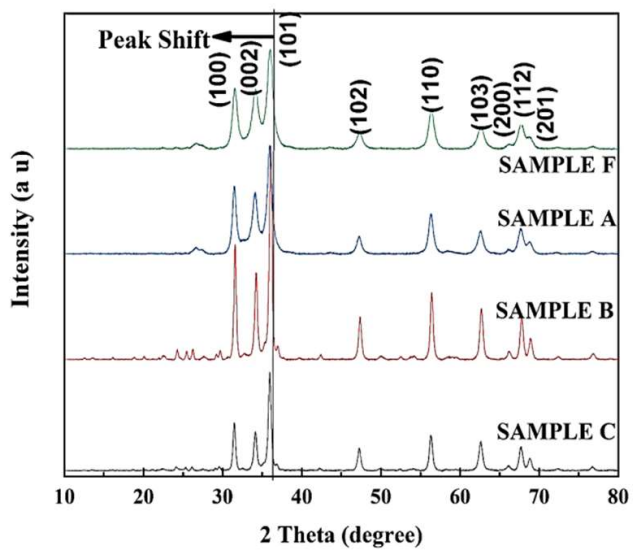

Fig.-3: XRD Patterns of the Samples F, A, B and C

The $2 \theta$ corresponding to (101) plane of the co-doped samples is summarised and presented in Table- 2 . The $2 \theta$ corresponding to (101) plane of pure undoped $\mathrm{ZnO}$ that we prepared is $36.45^{\circ}$. Concerning this value, all the prepared co-doped samples showed a shift in the peak towards the lower angle, revealing that the dopants $\mathrm{Ni}$ and $\mathrm{Mg}$ are well incorporated in the crystal lattice of $\mathrm{ZnO}$.

Table-2: The $2 \theta$ Corresponding to (101) Plane of the Co-doped Samples

\begin{tabular}{c|c|c|c|c}
\hline $\begin{array}{c}\text { Sample } \\
\text { Name }\end{array}$ & $\begin{array}{c}\text { Amount of } \\
\mathrm{ZnSO} \\
\text { gram in the feed }\end{array}$ & $\begin{array}{c}\text { Amount of } \\
\mathrm{NiSO}_{4} \mathrm{O} \text { in } \\
\text { gram in the feed }\end{array}$ & $\begin{array}{c}\text { Amount of } \\
\mathrm{MgSO}_{4} .7 \mathrm{H}_{2} \mathrm{O} \text { in } \\
\text { gram in the feed }\end{array}$ & $\begin{array}{c}2 \theta \text { in degree } \\
\text { corresponding } \\
\text { to (101) plane }\end{array}$ \\
\hline $\mathrm{C}$ & 2.875 & 0.2628 & 0.2464 & 35.96 \\
\hline $\mathrm{B}$ & 2.875 & 0.2628 & 0.4929 & 36.06 \\
\hline $\mathrm{A}$ & 2.875 & 0.2628 & 0.7394 & 35.95 \\
\hline $\mathrm{F}$ & 2.875 & 0.2628 & 0.9859 & 36.01 \\
\hline $\mathrm{D}$ & 2.875 & 0.5257 & 0.2464 & 36.04 \\
\hline
\end{tabular}

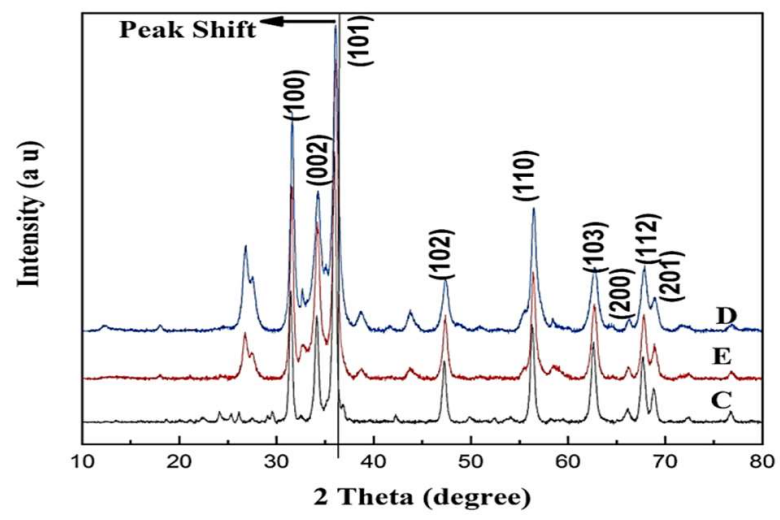

Fig.-4: XRD Patterns of the Samples D, E and C

1292 
RASĀYAN J. Chem.

Vol. 14 | No. 2 |1289-1296| April - June | 2021

There are reports that the lattice distortion due to the defects (vacancies, interstitials, substitutions, local structure transformations etc.) may cause the shift in the position of the XRD peak. Based on the type of strain, tensile or compressive, in the crystal, the peak position shifts, respectively, towards higher or lower angle. ${ }^{5,28}$ The shifting of the peak position to a lower angle with an increase or decrease of doping amount may indicate the expansion of the lattice parameters. ${ }^{29}$ The shift in the peak in the prepared co-doped samples towards lower angles further confirms the incorporation of the dopants, $\mathrm{Ni}$ and $\mathrm{Mg}$, in $\mathrm{ZnO}$ crystal lattice. ${ }^{30}$

\section{Calculation of Bandwidth}

The UV-visible spectral data of the co-doped $\mathrm{ZnO}$ were used for the bandwidth determination. Theoretical bandwidth energy can be evaluated using Tauc's relation. ${ }^{31}$ This relation is given by $\alpha \mathrm{h} v=\mathrm{D}$ $(\mathrm{h} v-\mathrm{E})^{\mathrm{n}}$. The value of $\mathrm{n}$ depends on the type of transition. That is, whether the transition is direct or indirect allowed transition or direct or indirect forbidden transition. In the present work, the value of $\mathrm{n}$ is equal to $1 / 2$ since in $\mathrm{ZnO}$ the transitions involved are direct allowed transitions. ${ }^{31}$ Now, the Tauc's relation for $\mathrm{ZnO}$ takes the form $(\alpha \mathrm{h} v)^{2}=\mathrm{D}^{2}(\mathrm{~h} v-\mathrm{E})$. Based on this relation, it is possible to have a plot of $(\alpha \mathrm{h} v)^{2}$ on ordinate vs. (hv) on the abscissa, the Tau plot. When the plot is extrapolated to abscissa, it will meet with a point on the abscissa; at this point $(\alpha \mathrm{h} v)^{2}$ is equal to zero. The value of (hv), usually in $\mathrm{eV}$, at this point on abscissa, will be equal to the bandwidth energy. ${ }^{31}$ Here in this work, the determination of bandwidth energy of all the prepared co-doped samples was carried out constructing Tau plot. The Tau plots are presented in Figures-5 to 10 for the co-doped samples, along with the Tau plot for pure undoped ZnO, Fig.-11.

The bandwidth of the pure undoped $\mathrm{ZnO}$ that we prepared is $3.19 \mathrm{eV}$ at room temperature. This value is less than the value available in the literature being $3.37 \mathrm{eV}$ at room temperature. Thus, the actual bandwidth energy depends on the way of preparing the sample. The result of bandwidth calculation for the prepared co-doped samples is summarised and presented in Table-3.

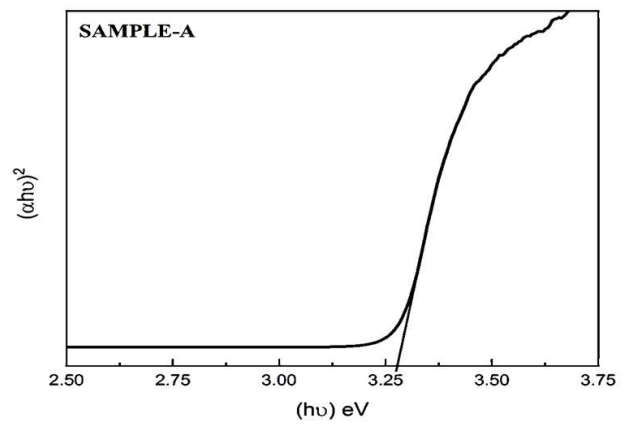

Fig.-5: Tau Plot for Sample A

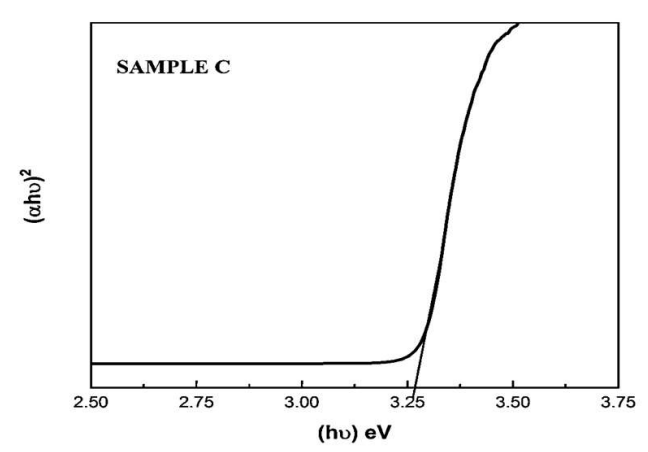

Fig.-7: Tau Plot for the Sample C

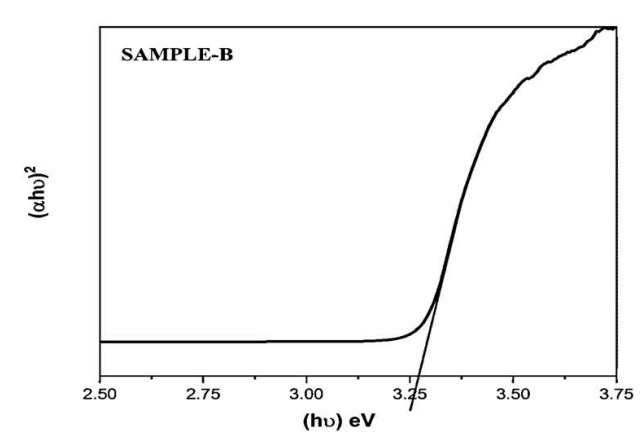

Fig.-6: Tau Plot for the Sample B

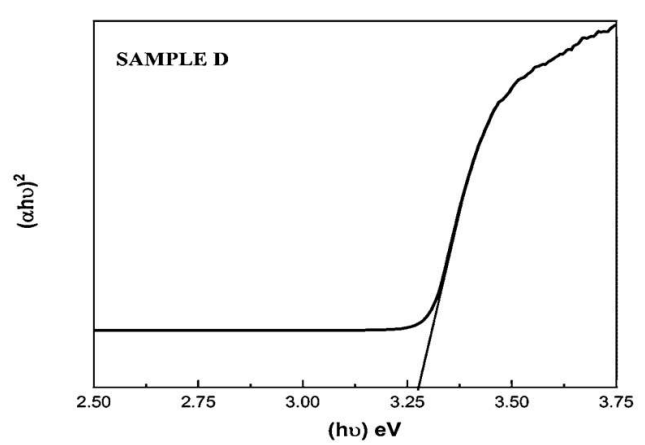

Fig.-8: Tau Plot for the Sample D 
RASĀYAN J. Chem.

Vol. 14 | No. 2 |1289-1296| April - June | 2021

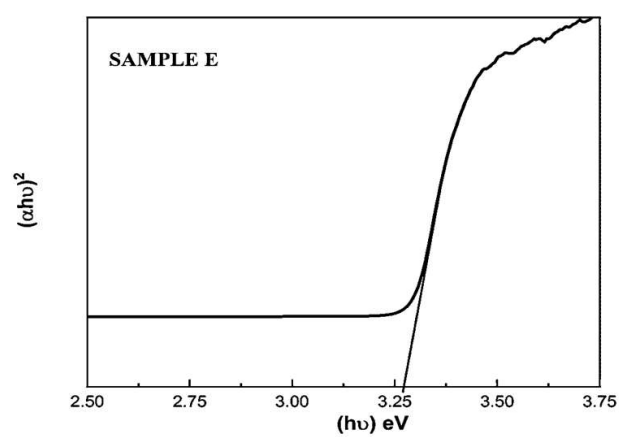

Fig.-9: Tau Plot for the Sample E

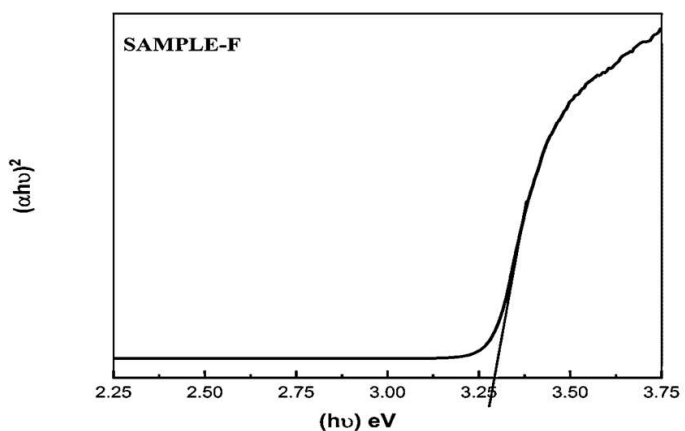

Fig.-10: Tau Plot for the Sample F

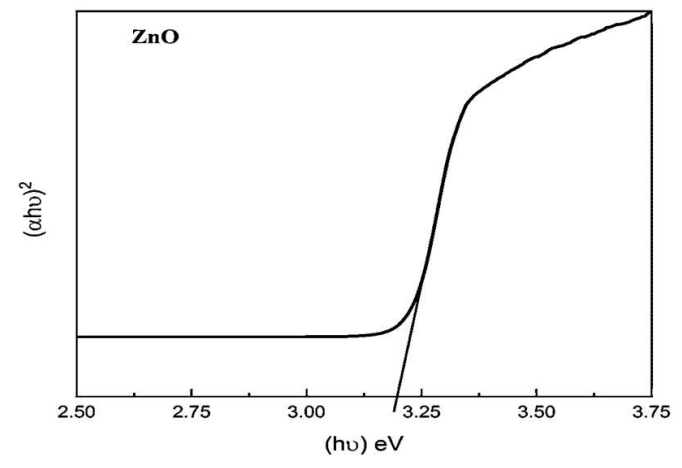

Fig.-11: Tau Plot for Pure Undoped $\mathrm{ZnO}$

From Table-3, it is clear that the bandwidth of the samples is greater than that of the pure undoped $\mathrm{ZnO}$ that we prepared, for this, it is $3.19 \mathrm{eV}$. Thus, the bandwidth of $\mathrm{ZnO}$ increases on co-doping with $\mathrm{Ni}$ and $\mathrm{Mg}$.

Table-3: Bandwidth of the Co-doped Samples

\begin{tabular}{c|c|c|c|c}
\hline $\begin{array}{c}\text { Sample } \\
\text { Name }\end{array}$ & $\begin{array}{c}\text { Amount of } \mathrm{ZnSO}_{4} .7 \mathrm{H}_{2} \mathrm{O} \\
\text { in gram in the feed }\end{array}$ & $\begin{array}{c}\text { Amount of } \\
\mathrm{NiSO}_{4} \cdot 6 \mathrm{H}_{2} \mathrm{O} \text { in gram } \\
\text { in the feed }\end{array}$ & $\begin{array}{c}\text { Amount of } \mathrm{MgSO}_{4} .7 \mathrm{H}_{2} \mathrm{O} \\
\text { in gram in the feed }\end{array}$ & $\begin{array}{c}\text { Bandwidth in } \\
\mathrm{eV}\end{array}$ \\
\hline $\mathrm{C}$ & 2.875 & 0.2628 & 0.2464 & 3.265 \\
\hline $\mathrm{B}$ & 2.875 & 0.2628 & 0.4929 & 3.27 \\
\hline $\mathrm{A}$ & 2.875 & 0.2628 & 0.7394 & 3.28 \\
\hline $\mathrm{F}$ & 2.875 & 0.2628 & 0.9859 & 3.29 \\
\hline $\mathrm{D}$ & 2.875 & 0.5257 & 0.2464 & 3.28 \\
\hline
\end{tabular}

Table-3 shows that for samples $\mathrm{C}, \mathrm{B}, \mathrm{A}$ and $\mathrm{F}$, the bandwidth energy increases as the amount of $\mathrm{MgSO}_{4} .7 \mathrm{H}_{2} \mathrm{O}$ in the feed increases keeping the amount of $\mathrm{NiSO}_{4} .6 \mathrm{H}_{2} \mathrm{O}$ fixed. Thus, it is clear that the bandwidth of $\mathrm{ZnO}$ increases as the amount of the dopant, $\mathrm{Mg}$ increases.

For samples $\mathrm{E}$ and $\mathrm{D}$, the bandwidth increases as the amount of $\mathrm{NiSO}_{4} \cdot 6 \mathrm{H}_{2} \mathrm{O}$ in the feed increases keeping the amount of $\mathrm{MgSO}_{4} .7 \mathrm{H}_{2} \mathrm{O}$ fixed. This again shows that the bandwidth of $\mathrm{ZnO}$ increases as the amount of the dopant, $\mathrm{Ni}$ increases in the crystal lattice of $\mathrm{ZnO}$. Thus, it can be very well concluded that the bandwidth of pure $\mathrm{ZnO}$ increases as the amount of $\mathrm{Ni}$ and $\mathrm{Mg}$ in the crystal lattice of $\mathrm{ZnO}$ increases. It is interesting to note from Table-3 that the bandwidth of samples $\mathrm{B}$ and $\mathrm{E}$ is the same even though the amount of $\mathrm{NiSO}_{4} \cdot 6 \mathrm{H}_{2} \mathrm{O}$ and the amount of $\mathrm{MgSO}_{4} \cdot 7 \mathrm{H}_{2} \mathrm{O}$ in the feed are different. That is, even though the amount of $\mathrm{Ni}$ and $\mathrm{Mg}$ in the crystal lattice of $\mathrm{ZnO}$, in these two samples, is different. Similar is the case with co-doped samples A and D. 
RASĀYAN J. Chem.

Vol. 14 | No. 2 |1289-1296| April - June | 2021

\section{CONCLUSION}

$\mathrm{Ni}$ and $\mathrm{Mg}$ co-doped $\mathrm{ZnO}$ were prepared following a chemical co-precipitation strategy. The co-doped samples were prepared to vary the amount of $\mathrm{Ni}$ and $\mathrm{Mg}$. Pure undoped $\mathrm{ZnO}$ was also prepared to adopt a chemical precipitation strategy. The co-doped samples were characterized by EDAX, powder XRD and $\mathrm{UV}$-visible analysis. The EDAX revealed the presence of $\mathrm{S}$ in the crystal lattice of co-doped $\mathrm{ZnO}$. The XRD supports this observation revealing the presence of the phase $\mathrm{Zn}_{3} \mathrm{O}\left(\mathrm{SO}_{4}\right)_{2}$ in the co-doped samples. The $2 \theta$ corresponding to (101) plane of pure undoped $\mathrm{ZnO}$ that we prepared is $36.45^{\circ}$. Concerning this value, all the prepared co-doped samples showed a shift in the peak towards the lower angle, revealing that the dopants $\mathrm{Ni}$ and $\mathrm{Mg}$ are well incorporated in the crystal lattice of $\mathrm{ZnO}$. On co-doping, the bandwidth of $\mathrm{ZnO}$ increases concerning that of pure undoped $\mathrm{ZnO}$ that we prepared. The bandwidth of the prepared co-doped samples was found to increase as the amount of the co-dopants increases.

\section{ACKNOWLEDGEMENT}

Acknowledgment is due to Sophisticated Analytical Instruments Facility, STIC, Cochin University P. O., Cochin, Kerala, India for the XRD analysis, School of Chemical Sciences, Mahatma Gandhi University, Kottayam, Kerala, India for UV-visible solid-state analysis, and Central Laboratory for Instrumentation and Facilitation (CLIF), University of Kerala, Trivandrum, Kerala, India for the EDAX analysis.

\section{REFERENCES}

1. J. M. D. Coey, M. Venkatesan and C. B. Fitzgerald, Nature Materials, 4, 173(2005), DOI: $10.1038 /$ nmat1310

2. http://www.tcd.ie/Physics/Magnetism/ Research/halfmetals.php

3. J. K. Furdyna, Journal of Applied Physics, 64, R29 (1988), DOI:10.1063/1.341700

4. S. D. Sarma, American Scientist, 89(6), 516(2001).

5. J. C. Fan, K. M. Sreekanth, Z. Xie, S. L. Chang and K. V. Rao, Progress in Materials Science, 58(6), 874(2013), DOI: 10.1016/j.pmatsci.2013.03.002

6. M. C. Sekhar, U. Chalapthi, V. K. Madhu Smitha, P. T. Poojitha, S. Uthanna and B. Poornaprakash, Journal of Superconductivity and Novel Magnetism, 30, 1937(2017), DOI:10.1007/s10948-0173992-x

7. S. Farhat, M. Rekaby and R. Awad, Journal of Superconductivity and Novel Magnetism, 31, 3051(2018), DOI:10.1007/s10948-017-4548-9

8. N. K. Divya and P. P. Pradyumnan, Materials Science in Semiconductor Processing, 41, 428(2016), DOI: 10.1016/j.mssp.2015.10.004

9. S. M. Hosseini, I. A. Sarsari, P. Kameli and H. Salamati, Journal of Alloys and Compounds, 640, 408(2015), DOI:10.1016/j.jallcom.2015.03.136

10. C. Jayachandraiah and G. Krishnaiah, Advanced Materials Letters, 6(8), 743(2015), DOI:10.5185/amlett.2015.5801

11. A. R. Nimbalkar, N. B. Patil, V. V. Ganbavle, S. V. Mohite, K. V. Madhale and M. G. Patil, Journal of Alloys and Compounds, 775, 466(2019), DOI:10.1016/j.jallcom.2018.10.144

12. W. Yu, D. Han, G. Cui, Y. Cong, J. Dong, X. Zhang, Y. Wang and S. Zhang, Japanese Journal of Applied Physics, 55(4S), 04EK05 (2016), DOI:10.7567/JJAP.55.04EK05

13. A. Ghosh, C. Zhang, S. Shi and H. Zhang, Sensors and Actuators B: Chemical, 301, 126958(2019), DOI: $10.1016 /$ j.snb.2019.126958

14. M. Hjiri, N. Zahmouli, R. Dhahri, S. G. Leonardi, L. El Mir and G. Neri, Journal of Materials Science: Materials in Electronics, 28, 9667(2017), DOI:10.1007/s10854-017-6717-9

15. R. Dhahri, S. G. Leonardi, M. Hjiri, L. El Mir, A. Bonavita, N. Donato, D. Iannazzo, and G. Neri, Sensors and Actuators B: Chemical, 239, 36(2017), DOI:10.1016/j.snb.2016.07.155

16. E. Hasabeldaim, O. M. Ntwaeaborwa, R. E. Kroon and H. C. Swart, Journal of Molecular Structure, 1192, 105(2019), DOI:10.1016/j.molstruc.2019.04.128 
RASĀYAN J. Chem.

Vol. 14 | No. 2 |1289-1296| April - June | 2021

17. U. Sachin Varma, P. Gautham, D. V. Ravikumar, K. M. Sreekanth, G. Sivasubramanian and K. M. Sreedhar, Rasayan Journal of Chemistry, 11(4), 1491(2018), DOI:10.31788/RJC.2018.1144000

18. P. Gautham, U. Sachin Varma, K. M. Sreekanth, D. V. Ravikumar, K. M. Sreedhar and G. Sivasubramanian, Asian Journal of Chemistry, 30(12), 2631(2018), DOI: $10.14233 /$ ajchem.2018.21488

19. M. Athira Chandran, N. Amal, K. M. Sreedhar, G. Sivasubramanian and K. M. Sreekanth, Rasayan Journal of Chemistry, 13(4), 2616(2020), DOI:10.31788/RJC.2020.1345859

20. U. Ozgur, Ya. I. Alivov, C. Liu, A. Teke, M. A. Reshehikov, S. Dogan, V. Avrutin, S. J. Cho and H. Morkoc, Journal of Applied Physics, 98, 041301 (2005), DOI:10.1063/1.1992666

21. C. Klingshirm, ChemPhysChem, 8(6), 782(2007), DOI:10.1002/cphc.200700002

22. C. W. Bunn, Proceedings of the Physical Society, 47(5), 835(1935), DOI:10.1088/0959$5309 / 47 / 5 / 307$

23. J. A. Rodriguez and M. Fernandez-Garcia, Synthesis, Properties, and Applications of Oxide Nanomaterials, Wiley (2007)

24. S. B. Zhang, S. H. Wei and A. Zunger, Physical Review B, 63, 075205(2001), DOI:10.1103/PhysRevB.63.075205

25. N. Goswami and D. K. Sharma, Physica E: Low-dimensional Systems and Nanostructures, 42(5), 1675(2010), DOI:10.1016/j.physe.2010.01.023

26. A. Sahai and N. Goswami, Physica E: Low-dimensional Systems and Nanostructures, 58, 130(2014), DOI: 10.1016/j.physe.2013.12.009

27. A. Sahai and N. Goswami, Ceramics International, 40(9), Part B, 14569(2014), DOI: 10.1016/j.ceramint.2014.06.041

28. A. Sahai, Y. Kumar, V. Agarwal, S. F. Olive-Méndez and N. Goswami, Journal of Applied Physics, 116, 164315(2014), DOI: 10.1063/1.4900721

29. C. Suryanarayana and M. Grant Norton, X-Ray Diffraction: A Practical Approach, (1998)

30. S. K. Neogi, S. Chattopadhyay, Aritra Banerjee, S. Bandyopadhyay, A. Sarkar and Ravi Kumar, Journal of Physics: Condensed Matter, 23(20), 205801(2011), DOI:10.1088/09538984/23/20/205801

31. J. Tauc, Amorphous and Liquid Semiconductors, (1974).

[RJC-6031/2020] 